\title{
FITUR PING MOBILE LEGENDS
}

\section{MOBILE LEGENDS PING FITUR}

Diana Perwitasari Sumarso ${ }^{*}$, Sukarelawati², Koesworo Setiawan ${ }^{3}$. ${ }^{123}$ Ps Sains Komunikasi Fakultas Ilmu Sosial dan Ilmu Politik, Universitas Djuanda Bogor, Jl. Tol Ciawi No 1 Kotak Pos 35 Bogor 16770.

*Korespondensi: Diana Perwitasari Sumarso, dianapurwitas@gmail.com

(Diterima oleh Dewan Redaksi: 01-02-2019)

(Dipublikasikan oleh Dewan Redaksi: 01-04-2019)

\begin{abstract}
This study discusses the students who use the Ping Mobile Legends online game feature, the method used is quantitative descriptive method and tested using Rank Sperman correlation. The research sample are Djuanda University communication science students consisting of 20 users of the Mobile Legends online game. The results of the study shows that (1) Users often use the Ping feature because it is only a click away, (2) The ping feature is often used by team players because it is easy, (3) The ping feature is the most favorite feature of every player, (4) The ping feature can smooth the game only with a click. The ping feature is very superior compared to other features and has the largest interpretation number 4 and is categorized well.
\end{abstract}

Keywords: Ping Features, Online Games, Students, Mobile Legends

\begin{abstract}
ABSTRAK
Penelitian ini membahas tentang mahasiswa pengguna fitur ping game online Mobile Legends, metode yang digunakan metode kuantitatif deskriptif dan diuji menggunakan korelasi Rank Sperman. Sampel penelitian ini dilakukan kepada mahasiswa ilmu komunikasi Universitas Djuanda terdiri dari 20 orang pengguna game online Mobile Legends. Adapun hasil penelitian menunjukan bahwa (1) Pengguna lebih sering menggunakan fitur Ping karena hanya sekali klik, (2) Fitur ping menjadi sering digunakan para pemain tim karena mudah, (3) Fitur ping merupakan kesukaan setiap pemain, (4) Hanya dengan sekali klik fitur ping memperlancar permainan. Fitur ping sangat unggul dibandingkan dengan fitur lainya dan memiliki angka penafsiran paling besar 4 dan berkategori baik.
\end{abstract}

Kata Kunci: Fitur Ping, Game online, Mahasiswa, Mobile Legends

Diana Perwitasari Sumarso, 2019. Fitur Ping Mobile Legends. 


\section{PENDAHULUAN}

Game adalah salah satu hiburan. Dari waktu ke waktu game semakin berkembang dan menarik untuk dimainkan. Game juga berguna untuk menghibur diri agar terlepas dari penat setelah beraktivitas. Pengguna dengan mudah mendapatkan game untuk dijalankan pada komputer atau smartphone. Game terbagi dua jenis, yaitu game online dan game offline. Game online memerlukan jaringan internet untuk memainkanya sedangkan game offline adalah game yang bisa digunakan pada komputer atau smartphone tanpa harus terhubung ke internet. Individu yang bermain game adalah gamers.

Para gamers didominasi oleh para remaja dan dewasa awal yang berusia 1525 tahun (Pratama, 2018). Kalangan remaja dan dewasa diatas salah satunya adalah mahasiswa, karena makin berkembangnya internet menjadi kebutuhan yang tidak terpisahkan dari berbagai media digital yang erat kaitannya dalam kehidupan manusia membawa pada era komunikasi yang termediasi. Hal menarik yang terjadi adalah media game sebagai media yang berfungsi memberi hiburan (Salamoon, 2014).

Seperti game online Mobile Legends yang menyuguhkan lima fitur komunikasi yang bisa digunakan oleh pemain, salah satunya adalah fitur ping. Fitur tersebut dapat memudahkan para pemain yang terdiri dari lima orang untuk saling berkomunikasi. Komunikasi yang dilakukan oleh pemain seperti mengirim pesan ping dengan mengklik menekan tombol ping yang ada di bawah mini map. misalnya untuk berkoordinasi dalam menyerang tim lawan atau saling membantu dan menjaga pemain lainnya agar tim menjadi kuat. Hal tersebut bisa dikatakan mampu mengasah komunikasi interpersonal para pemain. Tujuan penelitian untuk mengetahui fitur ping game online Mobie Legends yang digunakan mahasiswa.

\section{MATERI DAN METODE}

Pada metode penelitian, penulis menggunakan metode penelitian survey dan analisis korelasional. Populasi yang digunakan oleh penelitian ini adalah Mahasiswa Universitas Djuanda Bogor, Fakultas Ilmu Sosial Politik (FISIP), Ilmu Komunikasi semester 5 yang berjumlah 65 di kelas Reguler (Pagi), dan dari hasil observasi peneliti menemukan pengguna game online Mobile Legends terdiri dari 20 Orang. Sampel yang digunakan oleh peneliti adalah sampel jenuh, Adapun teknik pengumpulan data yang dilakukan menggunakan Kuesioner, Observasi, dan Interview (Wawancara). Data yang

telah dikumpulkan penulis pada penelitian ini menggunakan teknik analisis deskriptif, dengan menggunakan rumus WMS (Weight Mean Score) (Maudina,2018).

Berikut ini empat Indikator Fitur Ping yaitu:

1. Pengguna lebih sering menggunakan fitur Ping karena hanya sekali klik.

2. Fitur ping menjadi sering digunakan para pemain tim karena mudah.

3. Fitur ping merupakan kesukaan setiap pemain.

4. Hanya dengan sekali klik fitur ping memperlancar permainan.

\section{HASIL DAN PEMBAHASAN}

Fitur ping di Mobile Legends diaktifkan dengan cara menekan tombol ping yang ada di bawah mini map. Ketika tombol ping ditekan mini map akan membesar setelah itu pemain bisa meletakkan ping tersebut di manapun. Pada beberapa kondisi ping akan memberikan informasi spesifik. Misalnya ketika pemain melakukan ping pada turret tim maka pemain akan memberi isyarat defense turret tersebut.

Ping ini bisa digunakan untuk melakukan mark atau isyarat instan pada rekan satu tim. Sayangnya ping juga memiliki batasan. 
TABEL 1

Jawaban Pengguna Lebih Sering Menggunakan Fitur Ping Karena Hanya Sekali Klik.

\begin{tabular}{|c|c|c|c|c|c|}
\hline $\begin{array}{l}\text { Alternatif } \\
\text { Jawaban }\end{array}$ & $\mathbf{F}$ & $\%$ & $\begin{array}{l}\text { Skor } \\
\text { (x) }\end{array}$ & $f(x)$ & $\mathrm{M}=\frac{\sum \mathrm{f}(x)}{\mathrm{N}}$ \\
\hline $\begin{array}{l}\text { Sangat } \\
\text { Sering }\end{array}$ & 4 & $20 \%$ & 5 & 20 & \multirow{6}{*}{3.3} \\
\hline Sering & 3 & $15 \%$ & 4 & 12 & \\
\hline $\begin{array}{l}\text { Kadang- } \\
\text { Kadang }\end{array}$ & 8 & $40 \%$ & 3 & 24 & \\
\hline $\begin{array}{c}\text { Tidak } \\
\text { Pernah }\end{array}$ & 5 & $25 \%$ & 2 & 10 & \\
\hline $\begin{array}{c}\text { Sangat } \\
\text { Tidak } \\
\text { Pernah } \\
\end{array}$ & 0 & $0 \%$ & 1 & 0 & \\
\hline Jumlah & 20 & $100 \%$ & 15 & 66 & \\
\hline
\end{tabular}

Sumber : Hasil Penelitian, 2018

Tabel di atas menunjukan bahwa mayoritas responden yaitu sebanyak 8 (40\%) responden menjawab Sering bahwa Pengguna lebih sering menggunakan fitur Ping karena hanya sekali klik. Nilai akhir penafsiran yang diperoleh sebesar 3.3 dan berada dalam kategori Baik.

TABEL 2

Jawaban Fitur Ping Menjadi Kesukaan Para Pemain Tim Karena Mudah

\begin{tabular}{|c|c|c|c|c|c|}
\hline $\begin{array}{c}\text { Alternatif } \\
\text { Jawaban }\end{array}$ & $\mathbf{F}$ & $\%$ & $\begin{array}{l}\text { Skor } \\
(\mathrm{x})\end{array}$ & $\begin{array}{c}f \\
(x)\end{array}$ & $\mathrm{M}=\frac{\sum \mathbf{f}(\boldsymbol{x})}{\mathrm{N}}$ \\
\hline $\begin{array}{l}\text { Sangat } \\
\text { Sering }\end{array}$ & 7 & $10 \%$ & 5 & 35 & \multirow{6}{*}{4.25} \\
\hline Sering & 11 & $55 \%$ & 4 & 44 & \\
\hline $\begin{array}{l}\text { Kadang- } \\
\text { Kadang }\end{array}$ & 2 & $25 \%$ & 3 & 6 & \\
\hline $\begin{array}{c}\text { Tidak } \\
\text { Pernah } \\
\end{array}$ & 0 & $0 \%$ & 2 & 0 & \\
\hline $\begin{array}{c}\text { Sangat } \\
\text { Tidak } \\
\text { Pernah }\end{array}$ & 0 & $0 \%$ & 1 & 0 & \\
\hline Jumlah & 20 & $100 \%$ & 15 & 85 & \\
\hline
\end{tabular}

Sumber : Hasil Penelitian, 2018

Tabel di atas menunjukan bahwa mayoritas responden yaitu sebanyak 11 (55\%) responden menjawab Sering Fitur ping menjadi kesukaan para pemain tim karena mudah. Nilai akhir penafsiran yang diperoleh sebesar 4.25 dan berada dalam kategori Sangat Baik.
TABEL 3

Jawaban Fitur Ping Merupakan Kesukaan Setiap Pemain

\begin{tabular}{|c|c|c|c|c|c|}
\hline $\begin{array}{c}\text { Alternatif } \\
\text { Jawaban }\end{array}$ & $\mathbf{F}$ & $\%$ & $\begin{array}{l}\text { Skor } \\
(\mathrm{x})\end{array}$ & $\begin{array}{c}f \\
(x)\end{array}$ & $\mathrm{M}=\frac{\sum \mathrm{f}(\boldsymbol{x})}{\mathrm{N}}$ \\
\hline $\begin{array}{l}\text { Sangat } \\
\text { Sering }\end{array}$ & 6 & $30 \%$ & 5 & 30 & \multirow{6}{*}{4.05} \\
\hline Sering & 8 & $40 \%$ & 4 & 32 & \\
\hline $\begin{array}{l}\text { Kadang- } \\
\text { Kadang }\end{array}$ & 5 & $25 \%$ & 3 & 15 & \\
\hline $\begin{array}{c}\text { Tidak } \\
\text { Pernah }\end{array}$ & 2 & $10 \%$ & 2 & 4 & \\
\hline $\begin{array}{c}\text { Sangat } \\
\text { Tidak } \\
\text { Pernah }\end{array}$ & 0 & $0 \%$ & 1 & 0 & \\
\hline Jumlah & 20 & $100 \%$ & 15 & 81 & \\
\hline
\end{tabular}

Sumber : Hasil Penelitian, 2018

Tabel di atas menunjukan bahwa mayoritas responden yaitu sebanyak 8 (40\%) responden menjawab Sering. Fitur ping merupakan kesukaan setiap pemain. Nilai akhir penafsiran yang diperoleh sebesar 4.05 dan berada dalam kategori Baik.

TABEL 4 Jawaban Hanya Dengan Sekali Klik Fitur Ping Memperlancar Permainan

\begin{tabular}{|c|c|c|c|c|c|}
\hline $\begin{array}{c}\text { Alternatif } \\
\text { Jawaban }\end{array}$ & $\mathbf{F}$ & $\%$ & $\begin{array}{c}\text { Skor } \\
\text { (x) }\end{array}$ & $\begin{array}{c}f \\
(x)\end{array}$ & $\mathrm{M}=\frac{\sum \mathrm{f}(\boldsymbol{x})}{\mathrm{N}}$ \\
\hline $\begin{array}{l}\text { Sangat } \\
\text { Sering }\end{array}$ & 11 & $55 \%$ & 5 & 55 & \multirow{6}{*}{4.4} \\
\hline Sering & 7 & $35 \%$ & 4 & 28 & \\
\hline $\begin{array}{l}\text { Kadang- } \\
\text { Kadang }\end{array}$ & 1 & $5 \%$ & 3 & 3 & \\
\hline $\begin{array}{c}\text { Tidak } \\
\text { Pernah } \\
\end{array}$ & 1 & $5 \%$ & 2 & 2 & \\
\hline $\begin{array}{c}\text { Sangat } \\
\text { Tidak } \\
\text { Pernah } \\
\end{array}$ & 0 & $0 \%$ & 1 & 0 & \\
\hline Jumlah & 20 & $100 \%$ & 15 & 88 & \\
\hline
\end{tabular}

Sumber : Hasil Penelitian, 2018

Tabel di atas menunjukan bahwa mayoritas responden yaitu sebanyak 11 (55\%) responden menjawab Sangat Sering menggunakan Fitur ping hanya dengan sekali klik fitur ping memperlancar permainan. Nilai akhir penafsiran yang diperoleh sebesar 3.85 dan berada dalam kategori Sangat Baik. 


\section{KESIMPULAN DAN IMPLIKASI}

\section{Kesimpulan}

Fitur Ping game online Mobile Lagends berada dikategori baik yang artinya mahasiswa sering menggunakan fitur Ping game online Mobile Lagends untuk memenangkan permainan dalam satu tim.

\section{Implikasi}

Penelitian ini memiliki implikasi yaitu penggunaan perkembangan teknologi melalui game online Mobile Lagends.

\section{DAFTAR PUSTAKA}

Pratama, Fauzi dan Nuralam, 2018. Jurnal :Pengaruh nilai konsumsi terhadap keputusan pembeli (survei pada mahasiswa s1 aktif angkatan 2014/2015, 2015/2016, 2016/2017, dan 2017/2018 Program Studi Ilmu Administrasi Bisnis Jurusan Ilmu Administrasi Bisnis Fakultas Ilmu Administrasi Universitas Brawijaya yang membeli produk Virtual dalam online game. Malang :Fakultas Ilmu Administrasi Bisnis Universitas Brawijaya.

Salamoon, 2014. Jurnal : Studi Analisis Proses Interaksi Komunikasi Dalam Game Online "Dragon Nest" jurnal kajian media dan komunikasi. Surabaya : Petra Christian University.

Rahmah Maudina, Sukarelawati, Fitriah Maria, 2018. Hubungan antara kecendrungan mahasiswa menggunakan jenis aplikasi gadget dengan kepekaan sosial. Bogor : FISIP Universitas Djuanda. https://metaco.gg/mobile-

legends/panduan-mobile-legendsberkomunikasi-efektif.com(Diakses pada 20 September 2018). 